1 Universidade de Fortaleza (Unifor) Fortaleza (CE), Brasil. gracyremigio@gmail.com

2 Universidade Estadual de Campinas (Unicamp) - Campinas (SP), Brasil. anacarine.rolim@hotmail. com

3 Universidade de Fortaleza (Unifor) Fortaleza (CE), Brasil. mariavieira@bol.com.br

4 Universidade de Fortaleza (Unifor) Fortaleza, (CE), Brasil. janeeyre@unifor.br

\section{Atuação do cirurgião-dentista na identificação de maus-tratos contra crianças e adolescentes na atenção primária}

\author{
Dental surgeons' work in the identification of child and adolescent \\ abuse in primary health care
}

Gracyelle Alves Remigio Moreira1, Ana Carine Arruda Rolim², Maria Vieira de Lima Saintrain², Luiza Jane Eyre de Souza Vieira ${ }^{4}$

RESUMO Analisou-se a atuação do cirurgião-dentista na identificação de maus-tratos contra crianças e adolescentes na atenção primária e os fatores associados. Estudo transversal com 212 cirurgiões-dentistas em 85 municípios cearenses. Usou-se questionário com variáveis sociodemográficas, conhecimento, identificação e notificação de maus-tratos; remetido aos participantes via gestão municipal. Realizou-se análise bivariada e multivariada por regressão logística. Poucos profissionais identificaram maus-tratos, refletindo dificuldades para essa prática. As análises mostraram que ter pós-graduação e conhecer a ficha de notificação aumentou a chance de identificar maus-tratos.

PALAVRAS-CHAVE Maus-tratos infantis; Odontólogos; Atenção Primária à Saúde; Saúde coletiva.

\begin{abstract}
We analyzed the role of the dental surgeon in identifying child and adolescent maltreatment in primary care and associated factors. A cross-sectional study of 212 dentist-surgeons in 85 municipalities of Ceará. A questionnaire containing socio-demographic variables and information on knowledge, identification, and notification of maltreatment was sent to participants by the municipal manager. Bivariate and multivariate logistic regression analyses were performed. Few professionals identified maltreatment, indicating the difficulties of this practice. Analysis showed that having a post-graduation degree and knowing the notification form increased the chances of identifying maltreatment.
\end{abstract}

KEYWORDS Child Abuse; Dentists; Primary Health Care; Public health. 


\section{Introdução}

Os maus-tratos vêm atingindo um crescente número de crianças e adolescentes, de todas as idades e sexos, constituindo-se em um problema social e de saúde pública em vários países, inclusive no Brasil (FINKELHOR ET AL., 2013; MATOS; MARTINS, 2013). Os reflexos da violência são nitidamente percebidos no âmbito dos sistemas de saúde seja pelas mortes, traumas físicos e agravos mentais decorrentes do ato; pelo comprometimento da qualidade de vida dos indivíduos; pelos custos econômicos com tratamento e reabilitação ou pela necessidade de reorganização das práticas de saúde (OLIVEIRA ET AL., 2012). O tema tem ganhado visibilidade, estampando com frequência os noticiários nacionais, e o governo vem investindo na formulação de uma agenda de políticas e programas, nas diferentes áreas de atuação pública, para o enfrentamento do fenômeno.

Como parte do modelo de atenção à saúde brasileira, a Atenção Primária à Saúde (APS) se configura em um nível privilegiado para a identificação e o manejo de situações de maus-tratos dirigidas à população infantojuvenil (ROLIM ET AL., 2014), uma vez que se pauta em princípios que lançam o olhar sobre os determinantes de saúde da população, ampliando o seu campo de atuação.

O cirurgião-dentista, como integrante da Equipe de Saúde da Família, também é responsável por práticas que extrapolam o modelo técnico-curativista devido à complexidade das demandas da APS. Nesse contexto, esse profissional desempenha papel fundamental na prevenção, identificação, notificação e atenção às situações de maus-tratos. A literatura enfatiza sua posição estratégica para a detecção dos casos uma vez que a maioria das lesões se encontra na região da cabeça, pescoço, face e boca (ULDUM ET AL., 2010; AUSTIN, 2012; CARVALHO; GALO; SILVA, 2013).

No Brasil, o cirurgião-dentista tem o dever legal, ético e moral de notificar casos suspeitos ou confirmados de maus-tratos às autoridades competente, baseado no Estatuto da Criança e do Adolescente (ECA) (BRASIL, 1990), nas Portarias $n^{\circ} 1.968 / 2001$ (BRASIL, 2001) e $n^{0} 104 / 2011$ (BRASIL, 2011) do Ministério da Saúde, assim como no Código de Ética Odontológica, que constitui como deveres do profissional zelar pela saúde e pela dignidade do paciente, além de promover a saúde coletiva no desempenho de suas funções, cargos e cidadania, independentemente de exercer a profissão no setor público ou privado (CONSELHO FEDERAL DE ODONTOLOGIA, 2012).

Embora tenha havido avanços no campo legal e político, a maior parte dos cirurgiões-dentistas que trabalha na APS está despreparada para atuar ante os maus-tratos contra crianças e adolescentes, apresentando dificuldades para a identificação das situações e, consequentemente, para uma atenção adequada aos casos. Dessa forma, pode-se considerar que a instituição de preceitos legais e políticas públicas não garante uma atuação efetiva diante do fenômeno por parte desses profissionais. Isso mostra que a violência e suas repercussões se apresentam como desafio para os gestores do Sistema Único de Saúde (SUS).

A identificação de maus-tratos representa a fase primordial de atuação profissional para o enfrentamento do problema (PORTO; BISPO JÚNIOR; LIMA, 2014). O não reconhecimento das situações de violência vivenciadas por crianças e adolescentes impede a notificação dos casos e o acionamento da rede de proteção social, impossibilitando a cessação dos atos, o que contribui para o aumento de morbidade e mortalidade nessa faixa etária.

Nessa perspectiva, estudos que tragam ao debate essa realidade e que elenquem os fatores que facilitam a identificação de maus-tratos contra este grupo populacional tornam-se relevantes na medida em que podem oferecer subsídios para a superação de obstáculos que atravancam a implementação das normatizações e a qualificação das ações da APS diante do problema. 
Visando sobrepujar a distância entre o que está posto nos documentos oficiais e a prática nos serviços de saúde, este artigo tem como objetivo analisar a atuação do cirurgião-dentista na identificação de maus-tratos contra crianças e adolescentes no âmbito da APS e os fatores associados.

\section{Métodos}

Trata-se de um estudo de corte transversal, que utilizou como fonte de informações o banco de dados de uma pesquisa mais abrangente intitulada 'Violência envolvendo crianças e adolescentes: fatores condicionantes, processo de notificação e mecanismos de enfrentamento', realizada no contexto da APS com médicos, enfermeiros e cirurgiões-dentistas, em municípios cearenses. Este artigo se reporta, especificamente, à categoria dos cirurgiões-dentistas.

O estado do Ceará é composto por 184 municípios. Este estudo abrangeu 46,2\% destes, totalizando 85 cidades investigadas, contemplando todas as regiões de saúde do estado (figura 1).

Figura 1. Mapa do estado do Ceará evidenciando os municípios investigados, Ceará, Brasil, 2015

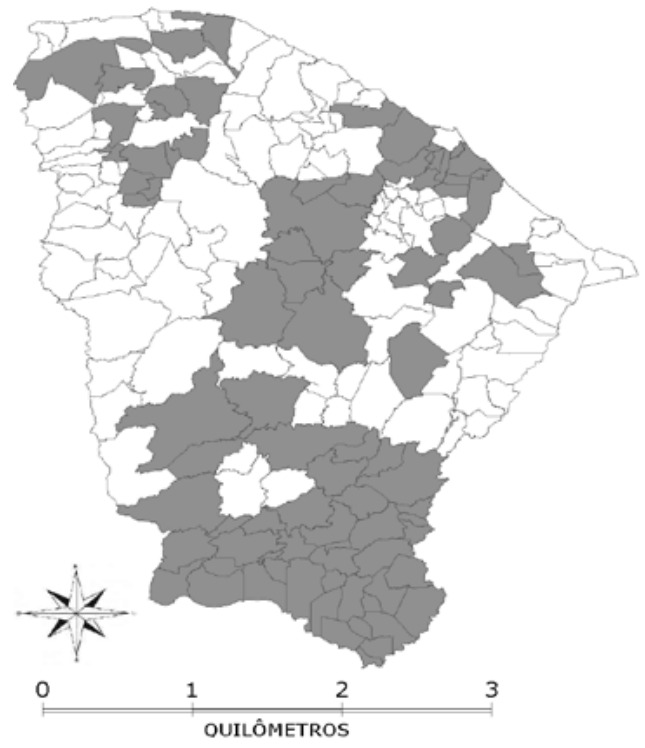

A população acessível foi obtida com base nos dados fornecidos pelo Departamento da Atenção Básica (DAB). Na época da pesquisa, os municípios referidos contavam com 714 cirurgiões-dentistas atuantes na APS. Para a produção de dados, um conjunto de cartas-convite, Termos de Consentimento Livre e Esclarecido (TCLE) e questionários foi enviado a todos os profissionais identificados. Destes, 212 responderam e compõe a amostra desta pesquisa.
A coleta de dados ocorreu entre os anos de 2010 a 2012, cuja operacionalização aconteceu por meio do envio dos formulários, previamente organizados em envelopes lacrados e identificados por município, aos gestores das Coordenadorias Regionais de Saúde e/ou das Secretarias Municipais de Saúde, que intermediaram a entrega do material aos cirurgiões-dentistas de cada município. O retorno dos instrumentos preenchidos seguiu o fluxo inverso. 
O questionário estruturado foi composto por 32 questões, adaptadas e revisadas, com os seguintes domínios analíticos: sociodemográfico, formação profissional, instrumentação e conhecimento sobre o tema, identificação e notificação de casos de maus-tratos em crianças e adolescentes.

Neste artigo, estabeleceu-se como desfecho a identificação de maus-tratos em crianças e adolescentes e como variáveis preditoras: sexo; idade; situação conjugal; tempo de formado; tempo de trabalho na APS; pós-graduação; sofreu maus-tratos na infância; participou de treinamento sobre o tema; conhece o ECA; conhece a ficha de notificação; ficha de notificação na Unidade de Atenção Primária à Saúde (Uaps); confia nos órgãos de proteção; sabe para onde encaminhar os casos; medo de envolvimento legal; lê sobre a temática; discute assunto no trabalho; conhece instituição de apoio; e vantagem em instituir à notificação na APS.

Para análise, o teste qui-quadrado (x2) foi utilizado para verificar a associação entre o desfecho e as variáveis preditoras. Estabeleceu-se $\mathrm{p}<0,05$ para significância estatística. Seguiram-se a essas análises os procedimentos de modelagem múltipla por meio de regressão logística, incluindo no modelo as variáveis preditoras que mostraram associação ao desfecho com significância $\mathrm{p}<0,25$. Permaneceram no modelo múltiplo as variáveis ao nível de significância $p<0,05$. A força de associação entre o desfecho e as variáveis preditoras foi expressa em valores estimados de $O d d s$ Ratio (OR) bruto e ajustado, com Intervalo de Confiança (IC) de 95\%. Todos os questionários foram conferidos e inseridos no banco com dupla entrada, a fim de verificar a consistência dos dados, que foram digitados no programa SPSS (SPSS Inc., Chicago, Estados Unidos), versão 17.0. A análise estatística foi realizada utilizando-se do programa STATA (Stata Corp LP, College Station, TX 77845, USA), versão 11.0.
A pesquisa foi aprovada pelo Comitê de Ética em Pesquisa da Universidade de Fortaleza - Unifor, sob o parecer $\mathrm{n}^{\circ}$ 072/2007.

\section{Resultados}

Os participantes do estudo ( $\mathrm{n}=212$ cirurgiões-dentistas) tinham entre 21 e 68 anos, com média de idade de 33,8 anos (DP $\pm 10,3)$ e maior frequência na faixa etária de 21 a 34 anos (128/60,4\%). Verificou-se o predomínio do sexo masculino (111/52,4\%), não casados (116/54,7\%), tempo de formado de 5 anos ou mais (121/57,1\%), com menos de 5 anos de trabalho na APS (107/50,5\%), com pós-graduação (144/67,9\%) e que não sofreram maus-tratos na infância (196/92,5\%).

As características referentes à instrumentação e ao conhecimento dos profissionais sobre os maus-tratos em crianças e adolescentes apontam que 178 (84,0\%) não conhecem a ficha de notificação, 158 (74,5\%) relataram que a Uaps não possui a ficha, 148 $(69,8 \%)$ confiam nos órgãos de proteção ao grupo, 106 (50,0\%) mencionaram saber para onde encaminhar os casos, 151 (71,2\%) referiram não ter medo de envolvimento legal ao notificar e 192 (90,6\%) acham vantagem instituir a notificação na APS.

Em relação à apropriação do tema pelos participantes, 183 (86,3\%) não participaram de treinamento acerca da temática, 115 $(54,2 \%)$ conhecem o ECA, 145 (68,4\%) não faziam leituras sobre a questão e responderam que o assunto não era discutido no ambiente de trabalho e 166 (78,3\%) não conheciam instituição de apoio às crianças e adolescentes em situação de maus-tratos.

Quanto à identificação e notificação de casos de maus-tratos, 71,2\% (151) dos cirurgiões-dentistas afirmaram que não haviam identificado situações de maus-tratos na sua prática profissional. Dos 28,3\% (60) que já tinham identificado algum caso, $83,1 \%$ não notificaram as ocorrências, enquanto $16,9 \%$ realizaram esse procedimento. 
Na tabela 1, na análise bivariada, observa-se que pós-graduação ( $\mathrm{p}=0,010)$, participar de treinamento $(p=0,024)$ e conhecer a ficha de notificação $(p=0,003)$ apresentaram associação com a identificação de maus-tratos. As demais variáveis não mostraram significância ( $p>0,05)$. No modelo logístico final, ter pós-graduação e conhecer a ficha de notificação permaneceram associadas ao desfecho.
O modelo logístico final mostrou que há mais chance de o cirurgião-dentista identificar situações de maus-tratos em crianças e adolescentes se tiver pós-graduação (2,35 vezes mais que aqueles que não possuem) e se conhecer a ficha de notificação (elevou quase o triplo, 2,93, a chance em relação àqueles que não conhecem a ficha) (tabela 1).

Tabela 1. Análise bivariada e multivariada entre a identificação de maus-tratos e fatores associados. Atenção Primária à Saúde, CE, Brasil, 2010-2012

\begin{tabular}{|c|c|c|c|c|c|c|c|c|}
\hline \multirow[b]{3}{*}{ Variável } & \multicolumn{4}{|c|}{$\begin{array}{c}\text { Cirurgião-dentista identificou } \\
\text { maus-tratos }\end{array}$} & & & & \\
\hline & \multicolumn{2}{|c|}{ Sim } & \multicolumn{2}{|c|}{ Não } & \multicolumn{2}{|c|}{ Não Ajustada } & \multicolumn{2}{|c|}{ Ajustada (modelo final) } \\
\hline & $\mathbf{N}$ & $\%$ & $\mathbf{N}$ & $\%$ & OR (IC95\%) & $\mathbf{p}$ & OR (IC95\%) & $\mathbf{p}$ \\
\hline \multicolumn{9}{|l|}{$\operatorname{Sexo}(n=211)$} \\
\hline Masculino & 32 & 53,3 & 79 & 52,3 & & & & \\
\hline Feminino & 28 & 46,7 & 72 & 47,7 & $0,96(0,50-1,82)$ & 0,894 & & \\
\hline \multicolumn{9}{|l|}{ Idade $(n=191)$} \\
\hline 21-34 anos & 39 & 69,6 & 89 & 65,9 & $1,18(0,57-2,48)$ & 0,618 & & \\
\hline$>34$ anos & 17 & 30,4 & 46 & 34,1 & & & & \\
\hline \multicolumn{9}{|c|}{ Situação conjugal $(n=210)$} \\
\hline Casado & 30 & 50,8 & 64 & 42,4 & $1,40(0,73-2,68)$ & 0,267 & & \\
\hline Não casado & 29 & 49,2 & 87 & 57,6 & & & & \\
\hline \multicolumn{9}{|c|}{ Tempo de formado $(n=211)$} \\
\hline$<5$ anos & 26 & 43,3 & 65 & 43,1 & & & & \\
\hline$\geq 5$ anos & 34 & 56,7 & 86 & 56,9 & $0,98(0,51-1,89)$ & 0,969 & & \\
\hline \multicolumn{9}{|c|}{ Tempo de trabalho na APS $(n=211)$} \\
\hline$<5$ anos & 32 & 53,3 & 75 & 49,7 & & & & \\
\hline$\geq 5$ anos & 28 & 46,7 & 76 & 50,3 & $0,86(0,45-1,64)$ & 0,631 & & \\
\hline \multicolumn{9}{|c|}{ Pós-Graduação (n=208) } \\
\hline Sim & 49 & 81,7 & 94 & 63,5 & $2,55(1,18-5,90)$ & 0,010 & $2,35(1,11-4,97)$ & 0,024 \\
\hline Não & 11 & 18,3 & 54 & 36,5 & & & & \\
\hline \multicolumn{9}{|c|}{ Sofreu maus-tratos na infância $(n=210)$} \\
\hline Sim & 06 & 10,0 & 09 & 6,0 & $1,74(0,48-5,76)$ & 0,309 & & \\
\hline Não & 54 & 90,0 & 141 & 94,0 & & & & \\
\hline \multicolumn{9}{|c|}{ Participou de treinamento $(n=210)$} \\
\hline $\operatorname{Sim}$ & 13 & 21,7 & 15 & 90,0 & $2,48(1,00-6,05)$ & 0,024 & & \\
\hline Não & 47 & 78,3 & 135 & 10,0 & & & & \\
\hline \multicolumn{9}{|c|}{ Conhece o ECA $(n=210)$} \\
\hline Sim & 39 & 65,0 & 76 & 50,7 & $1,80(0,93-3,55)$ & 0,059 & & \\
\hline Não & 21 & 35,0 & 74 & 49,3 & & & & \\
\hline \multicolumn{9}{|c|}{ Conhece ficha de notificação $(n=209)$} \\
\hline Sim & 16 & 26,7 & 16 & 10,7 & $3,02(1,28-7,02)$ & 0,003 & $2,93(1,32-6,48)$ & 0,008 \\
\hline Não & 44 & 73,3 & 133 & 89,3 & & & & \\
\hline \multicolumn{9}{|c|}{ Ficha de notificação na Uaps ( $n=205)$} \\
\hline Sim & 17 & 28,8 & 31 & 21,2 & $1,50(0,70-3,13)$ & 0,245 & & \\
\hline Não & 42 & 71,2 & 115 & 78,8 & & & & \\
\hline Confia nos órga & & & & & & & & \\
\hline
\end{tabular}




\begin{tabular}{|c|c|c|c|c|c|c|}
\hline Sim & 43 & 71,7 & 104 & 73,8 & $0,89(0,43-1,89)$ & 0,759 \\
\hline Não & 17 & 28,3 & 37 & 26,2 & & \\
\hline \multicolumn{7}{|c|}{ Sabe para onde encaminhar $(n=199)$} \\
\hline Sim & 32 & 55,2 & 74 & 52,5 & $1,11(0,57-2,16)$ & 0,729 \\
\hline Não & 26 & 44,8 & 67 & 47,5 & & \\
\hline \multicolumn{7}{|c|}{ Medo de envolvimento legal $(n=204)$} \\
\hline Sim & 18 & 30,5 & 36 & 24,8 & & \\
\hline Não & 41 & 69,5 & 109 & 75,2 & $0,75(0,36-1,57)$ & 0,404 \\
\hline \multicolumn{7}{|c|}{ Lê sobre a temática $(n=207)$} \\
\hline Sim & 23 & 38,3 & 40 & 27,2 & $1,66(0,83-3,27)$ & 0,114 \\
\hline Não & 37 & 61,7 & 107 & 72,8 & & \\
\hline \multicolumn{7}{|c|}{ Discute assunto no trabalho $(n=208)$} \\
\hline Sim & 26 & 43,3 & 38 & 25,7 & $2,21(1,11-4,34)$ & 0,012 \\
\hline Não & 34 & 56,7 & 110 & 74,3 & & \\
\hline \multicolumn{7}{|c|}{ Conhece instituição de apoio (n=205) } \\
\hline Sim & 13 & 21,7 & 27 & 18,6 & $1,20(0,52-2,67)$ & 0,616 \\
\hline Não & 47 & 78,3 & 118 & 81,4 & & \\
\hline \multicolumn{7}{|c|}{ Vantagem notificação na APS ( $n=207$ ) } \\
\hline $\operatorname{Sim}$ & 55 & 91,7 & 136 & 92,5 & $0,88(0,26-3,42)$ & 0,835 \\
\hline Não & 05 & 8,3 & 11 & 7,5 & & \\
\hline
\end{tabular}

\section{Discussão}

A atuação na APS pressupõe vantagens para a identificação de maus-tratos contra crianças e adolescentes tendo em vista a proximidade territorial e o vínculo dos profissionais com as famílias. Contudo, os resultados deste estudo revelam que uma pequena parcela dos cirurgiões-dentistas identificou alguma situação de maus-tratos na sua prática nesse âmbito. Este fato reflete a existência de dificuldades na identificação dos casos.

Trabalhos estrangeiros também mostram baixo percentual de cirurgiões-dentistas que detectaram ou suspeitaram de atos violentos contra a população infanto-juvenil (ULDUM ET AL., 2010; SONBOL ET AL., 2012). Achados semelhantes também são verificados em pesquisas nacionais (FRACON; SILVA; BREGAGNOLO, 2011; CARVALHO; GALO; SILVA, 2013). A inabilidade do profissional em identificar os maus-tratos pode ser atribuída a fatores, como: ausência ou insuficiência de abordagem do tema na graduação e em treinamentos profissionais; conduta clínica baseada no modelo biomédico; naturalização da violência contra crianças e adolescentes; assim como pela própria organização do processo de trabalho na APS.

Apesar do esforço do setor saúde em recomendar as ações e práticas de identificação, notificação, tratamento e prevenção às várias expressões da violência doméstica, a capacitação de recursos humanos para tais condutas ainda é limitada. Esta fragilidade inicia-se na formação desses profissionais, pois essas questões dificilmente são introduzidas nas matrizes curriculares da graduação.

Carvalho, Galo e Silva (2013), em um estudo empreendido com 80 cirurgiões-dentistas da rede pública e privada de saúde de um município do estado de São Paulo, constataram que a maioria dos profissionais relatou que $o$ assunto não foi abordado durante a graduação. Fracon, Silva e Bregagnolo (2011) ressaltam que, mesmo tendo recebido informações durante a graduação, quase a totalidade dos profissionais investigados as consideraram insuficientes.

Também se evidencia que a lacuna do conhecimento ultrapassa os limites das instituições formadoras e se estende para a rotina das 
unidades de saúde, em virtude de a temática da violência ainda ser pouco trabalhada ou até mesmo estar ausente da pauta de educação permanente dos serviços (MOREIRA ET AL., 2014). Confirmando este argumento, neste estudo, $86,3 \%$ dos cirurgiões-dentistas não participaram de treinamento acerca do tema e $68,4 \%$ não faziam leituras sobre a questão e relataram que o assunto não era discutido no ambiente de trabalho. Isto indica que o enfoque na questão dos maus-tratos na APS ocorre de forma incipiente, pontual e assistemática. Em razão desses aspectos, os profissionais sentem-se inseguros e despreparados para a detecção e para a condução desse tipo de ocorrência.

Outra questão é que a prática de atenção à saúde bucal no SUS está fortemente pautada no modelo clínico (ARAúJo; DIMENSTEIN, 2006; DECARLI ET AL., 2014). Esse perfil clínico preponderante vai de encontro às características preconizadas pelo modo de produzir saúde na APS (ARAújo; DIMENSTeIN, 2006). A reprodução de práticas tradicionais, fragmentadas e isoladas, fundadas na lógica de atendimento clínico-biológico, voltado para o tratamento de lesões físicas, restringe uma atuação adequada ante os casos de violência.

A dificuldade em identificar crianças e adolescentes em situação de maus-tratos atrela-se ao fato de a demanda explícita, no que concerne ao atendimento por este motivo, ser considerada baixa, apesar dos altos índices desse problema nos territórios adscritos (PORTO; BISPO JÚNIOR; LIMA, 2014), enquanto os casos velados, sem sinais visíveis, manifestam-se como empecilhos para o reconhecimento da violência. Guedes, Nogueira e Camargo Jr. (2009), ao discorrerem sobre as limitações do modelo biomédico diante de pacientes com sintomas indefinidos, argumentam que o obstáculo de desvelar o não aparente está relacionado com a formação baseada nesse modelo hegemônico, que não valoriza os aspectos subjetivos, e com a singularidade do sofrimento humano.

Nesse sentido, a atuação dos profissionais diante dos maus-tratos está vinculda, com frequência, àquilo que se consegue visualizar como lesões e traumas resultantes das agressões. Diante da complexidade do fenômeno e de suas múltiplas dimensões, tem-se a necessidade de uma abordagem que priorize a execução da clínica ampliada e que viabilize o desenvolvimento de uma atenção integral ao indivíduo (PORTO; BISPO JÚNIOR; LIMA, 2014).

Ressaltam-se, além disso, o fato de que aspectos culturais, valores e tabus também podem influenciar intensamente a identificação de maus-tratos. Culturalmente, ainda parece ser aceita a concepção do direito sem limites dos cuidadores sobre as crianças e os adolescentes, o que leva ao abuso de poder do mais forte sobre o mais fraco. $\mathrm{O}$ uso da punição física ou outras expressões de violência ainda constituem instrumentos frequentemente utilizados na educação dos filhos. Consequentemente, essa banalização da violência física faz com que práticas abusivas, muitas vezes, sejam consideradas como práticas normais de disciplinamento, até mesmo pelos profissionais de saúde.

Outra barreira para a detecção dos casos diz respeito à própria organização do processo de trabalho na APS. A sobrecarga de atribuições incorporadas pelos profissionais, a elevada quantidade de famílias por equipe, o processo de avaliação de desempenho centrado na produtividade e o excesso de atividades burocráticas são questões que fragilizam a atenção em saúde dispensada aos usuários do serviço. Esse acúmulo de atribuições reflete, muitas vezes, a realização de atendimentos rápidos, superficiais e focados na sintomatologia, sem a devida atenção às causas do problema (PORTO; BISPO JÚNIOR; LIMA, 2014). De acordo com Porto, Bispo Júnior e Lima (2014), as limitações dos profissionais para lidar com o problema também acentuam obstáculos dos pacientes ou pessoas da comunidade enxergarem as Uaps como local de apoio e acompanhamento às situações de violência.

O presente estudo também elucida os fatores que facilitam a identificação, pelos cirurgiões-dentistas, de maus-tratos contra 
crianças e adolescentes na realidade estudada. A análise múltipla mostrou que ter pós-graduação e conhecer a ficha de notificação aumentou a chance de os profissionais identificarem os casos.

Esses achados ressaltam a importância da academia na formação de profissionais que possam, de forma ética e científica, contribuir na vigilância em saúde das pessoas durante o exercício da profissão. Supõe-se que as propostas curriculares das pós-graduações construídas em eixos interdisciplinares favoreçam a troca de saberes e experiências profissionais ante as demandas sociais que estão inscritas nas políticas temáticas e que desafiam a efetividade da gestão em saúde.

Nessa compreensão, os Ministérios da Saúde e da Educação incentivam a implantação de residências e pós-graduações de caráter interdisciplinar para que as diretrizes políticas, que norteiam a reorientação do modelo de atenção à saúde, alcancem resultados que transformem os indicadores de saúde da população, especificamente nesta pesquisa, dos que apontam os altos índices de maus-tratos em crianças e adolescentes.

Tradicionalmente, a área da saúde tem concentrado esforços em atender os efeitos da violência: a reparação dos traumas e lesões físicas nos serviços de emergência, na atenção especializada, nos processos de reabilitação, nos aspectos médico-legais e nos registros de informações. Ultimamente, sobretudo em relação a alguns agravos, como violência contra a população infanto-juvenil, amplia-se a abordagem que inclui aspectos psicossociais e psicológicos tanto em relação ao impacto sobre os indivíduos como em relação à caracterização do agressor.

A violência doméstica é um assunto muito sensível, e relatar suspeita de maus-tratos é um tópico circunspecto para profissionais de Odontologia. Cirurgiões-dentistas podem desempenhar um papel importante para interromper o ciclo de maus-tratos, visto que $75 \%$ das lesões físicas têm assento na cabeça, pescoço, face e/ou boca (AUSTIN, 2012).
Além disso, a negligência na saúde bucal pode ser um indicador de violência doméstica. Crianças e adolescentes em situação deste tipo de violência podem ser restringidos (pelos seus agressores) de atividades de higiene diárias normais, atendimento odontológico ou médico, resultando em patologias não tratadas, dor e/ou dor crônica, infecção, traumas, entre outras, afetando a sua qualidade de vida. Trabalho analisando a relação entre cárie dentária e negligência em crianças detectou relação entre experiência de cárie e fatores de risco sugestivos de negligência, tendo sido importante na APS para a orientação de seus cuidadores (LOURENÇO; SAINTRAIN; VIEIRA, 2013).

Os cirurgiões-dentistas, ao identificarem uma situação de violência, devem notificar o caso, assim como determinar se um paciente pediátrico/adolescente requer avaliação mais detalhada ou uma intervenção. Para tanto, os profissionais precisam de conhecimento aprofundado, ferramentas didáticas e clínicas que possam ajudá-los a identificar os sinais e sintomas de violência doméstica. Na visão de Austin (2012), cada prática no aprendizado odontológico pode determinar estratégias adequadas para a intervenção e comunicação com o paciente vítima de violência. Afirmação esta que corrobora os achados desta pesquisa de que os profissionais tendo pós-graduação apresentam 2,35 mais chances de detectar a violência quando comparado aos que não possuem esta formação.

O conhecimento generalista e humanizado do cirurgião-dentista é efetivo para contribuir na sua atuação de maneira preventiva, identificando crianças e adolescentes maltratados, quer física ou negligencialmente. De modo importuno, ainda há falta de informação e desconhecimento destes profissionais no que tange à violência contra essa faixa etária. Estudo brasileiro com cirurgiões-dentistas acerca do tema revela que a grande maioria $(84,2 \%)$ não recebeu orientações na graduação ou após a graduação 
(FRACON; SILVA; BREGAGNOLO, 2011), justificando o alerta dos pesquisadores quanto à necessidade de capacitação dos trabalhadores da área de saúde para diagnosticar, conduzir o atendimento nos casos de maus-tratos e comunicar às autoridades competentes.

Outro aspecto que favoreceu a identificação de maus-tratos foi o conhecimento da ficha de notificação da violência. A notificação é o processo que visa interromper atitudes violentes no plano familiar ou por parte de qualquer agressor, a partir do acionamento dos órgãos competentes, como o Conselho Tutelar. Este procedimento também fornece subsídios para a formulação de políticas públicas, tendo em vista o dimensionamento epidemiológico do problema (MOREIRA ET AL., 2014).

A ficha de notificação funciona como importante fonte de comunicação entre a Secretaria de Saúde, o Conselho Tutelar e o profissional ou equipe de saúde que tiveram contato próximo com a criança ou o adolescente, sua família e que diagnosticaram o ato de violência. Esse instrumento foi instituído e padronizado no âmbito do SUS e orienta a coleta de informações e a condução dos casos (BRASIL, 2001, 2011).

Os cirurgiões-dentistas, comprometidos com a promoção da saúde da população e preocupados com a garantia dos direitos da criança e do adolescente, muitas vezes têm dúvidas quanto à maneira correta de agir. Por esse motivo, protocolos de orientação profissional são importantes para apoiá-los no diagnóstico, registro e notificação dos casos de violência, favorecendo maior segurança para a sua identificação.

Rolim et al. (2014) argumentam que a existência de protocolos que firmem condutas na unidade de saúde propicia a instrumentação dos profissionais para a atuação no tema. Por essa razão, a gestão deve assegurar, no mínimo, o material necessário para uma prática de qualidade na APS. O fato de que conhecer a ficha de notificação ter aumentado em quase três vezes a chance de o cirurgião-dentista detectar maus-tratos, neste estudo, revela a importância da disposição desse instrumento nas unidades de saúde. De forma contrária, a insuficiência de insumos pode comprometer o fluxo de atendimento, inviabilizando condutas que culminem com soluções preconizadas na legislação (ROLIM ET AL., 2014).

Reconhece-se os investimentos das esferas de governo ao legislarem e promulgarem políticas de enfrentamento às violências direcionadas à população infanto-juvenil. Entretanto, a sua divulgação e 'empoderamento' por parte dos profissionais parece não ter sido suficiente para a efetivação das diretrizes e consequente reorientação de uma prática predominantemente clínica para uma centrada no sujeito, considerando as singularidades que emergem das demandas sociais.

Autores enfatizam que os cirurgiões-dentistas reconhecem a importância do seu papel no que se refere à condução de casos de violências no grupo pediátrico e hebiátrico, entretanto, apresentam dificuldades na identificação e em como conduzir os procedimentos ante essas casuísticas (CARVALHO; GALO; SILVA, 2013).

Assume-se que esta pesquisa apresenta como limitação a taxa de devolução dos questionários, perfazendo um percentual de $29,7 \%$. Este valor pode estar relacionado com a sobrecarga de trabalho dos profissionais, com a complexidade do objeto de investigação, com a falta de interesse e formação no assunto ou até mesmo com o não reconhecimento da realização de pesquisas como um dos dispositivos que contribui para a reorientação do modelo de atenção à saúde em acordo com o que preconiza a legislação do SUS.

Dessa forma, os resultados do estudo podem não representar, em sua totalidade, a prática dos cirurgiões-dentistas das regiões de saúde investigadas, não sendo possível sua generalização. Todavia, vale salientar que os dados apresentados estão 
em consonância com a literatura sobre o tema, até mesmo com pesquisas empreendidas em outros níveis de atenção à saúde e no cenário internacional.

\section{Conclusão}

A maior parte dos cirurgiões-dentistas que atua na APS dos municípios investigados não identificou situações de maus-tratos contra crianças e adolescentes na sua prática profissional. O modelo logístico final evidenciou que fatores, como ter pós-graduação e conhecer a ficha de notificação, facilitam a detecção dos casos pelos profissionais.

Nesse sentido, o estudo aponta proposições que devem ser consideradas no redirecionamento de políticas que reorganizam as redes de atenção à saúde, no planejamento das ações e, sobretudo, na gestão. Entendese que é imperioso ampliar as discussões nos cursos de graduação e sistematizar a educação permanente como instrumento transformador das demandas sociais que aportam os cenários da APS, apropriando-se dos conteúdos das políticas de enfrentamento às múltiplas facetas com que as violências se desdobram.

Há ainda que se considerar a necessidade de mudanças nas abordagens realizadas pelos profissionais, para não priorizarem apenas o cumprimento de metas e a execução das técnicas propostas pelos programas e observarem os aspectos subjetivos que circunscrevem as 'queixas dolorosas' que adentram os consultórios odontológicos no âmbito da APS. Em conclusão, os processos de trabalho nesse contexto demandam uma gestão incisiva, comprometida com a qualidade científica, técnica e ética.

\section{Referências}

\begin{abstract}
ARAÚJO, Y. P.; DIMENSTEIN, M. Estrutura e organização do trabalho do cirurgião-dentista no PSF de municípios do Rio Grande do Norte. Ciência \& Saúde Coletiva, Rio de Janeiro, v. 11, n. 1, p. 219-227, jan./mar. 2006.
\end{abstract}

AUSTIN, M. Domestic Violence. 2012. Disponível em: <https://dentallearning.org/course/DomesticViolence/ Domestic\%20Violence.pdf>. Acesso em: 20 abr. 2015.

BRASIL. Presidência da República. Lei 8.069, de 13 de julho de 1990. Dispõe sobre o Estatuto da Criança e do Adolescente e dá outras providências. Brasília, DF: Presidência da República, 1990.

Ministério da Saúde. Portaria MS/GM n ${ }^{\circ} 1.968$, de 25 de outubro de 2001. Dispõe sobre a notificação, às autoridades competentes, de casos de suspeita ou de confirmação de maus-tratos contra crianças e adolescentes atendidos nas entidades do Sistema Único de Saúde. Diário Oficial [da] União, Brasília, DF, 25 out. 2001, n. 206, Seção 1, p. 86.
Ministério da Saúde. Portaria n ${ }^{\circ}$ 104, de 25 de janeiro de 2011. Define as terminologias adotadas em legislação nacional, a relação de doenças, agravos e eventos em saúde pública de notificação compulsória em todo território nacional e estabelece fluxos, critérios, responsabilidades e atribuições aos profissionais de saúde. Diário Oficial [da] União. Brasília, DF, 25 jan. 2011. Disponível em: <http://bvsms.saude.gov.br/ bvs/saudelegis/gm/2011/prt0104_25_01_2011.html>. Acesso em: 26 out. 2015

CARVALHO, L. M. F.; GALO, R.; SILVA, R. H. A. O cirurgião-dentista frente à violência doméstica: conhecimento dos profissionais em âmbito público e privado. Revista Faculdade de Medicina Ribeirão Preto, São Paulo, v. 46, n. 3, p. 297-304, set. 2013.

CONSELHO FEDERAL DE ODONTOLOGIA. Código de Ética Odontológica. 2012. Disponível em: <http://cfo. org.br/legislacao/codigos/>. Acesso em: 10 abr. 2015. 
DECARLI, A. D. et al. Visita domiciliar e cuidado domiciliar na Atenção Básica: um olhar sobre a saúde bucal. Saúde em Debate, Rio de Janeiro, v. 39, n. 105, p. 441-450, 2014.

FINKELHOR, D. et al. Violence, crime, and abuse exposure in a national sample of children and youth: an update. JAMA Pediatria, Chicago, v. 167, n. 7, p. 614621, may/jul. 2013.

FRACON, E. T.; SILVA, R. H. A.; BREGAGNOLO, J. C. Avaliação da conduta do cirurgião-dentista ante a violência doméstica contra crianças e adolescentes no município de Cravinhos (SP). RSBO, Santa Catarina, v. 8, n. 2, p. 153-159, abr./jun. 2011.

GUEDES, C. R.; NOGUEIRA, M. I.; CAMARGO JR,

K. R. Os sofredores de sintomas indefinidos: um desafio para a atenção médica. Physis Revista de Saúde Coletiva, Rio de Janeiro, v. 19, n. 3, p. 797-815, mar. 2009.

LOURENÇO, C. B.; SAINTRAIN, M. V. L.; VIEIRA, A. P. G. F. Child, neglect and oral health. BMC Pediatrics, Londres, v. 13, n. 188, p. 1-8, 2013.

MATOS, K. F.; MARTINS, C. B. G. Mortalidade por causas externas em crianças, adolescentes e jovens: uma revisão bibliográfica. Revista espaço para a saúde, Londrina, v. 14, n. 1, p. 82-93, dez. 2013.

MOREIRA, G. A. R. et al. Fatores associados à notificação de maus-tratos em crianças e adolescentes na atenção básica. Ciência \& Saúde Coletiva, Rio de Janeiro, v. 19, n. 10, p. 4267- 4276, dez. 2014.
OLIVEIRA, M. T. et al. Violência intrafamiliar: a experiência dos profissionais de saúde nas Unidades de Saúde da Família de São Joaquim do Monte, Pernambuco. Rev. Bras. Epidemiol., São Paulo, v. 15, n. 1, p. 166-178, 2012.

PORTO, R. T. S.; BISPO JÚNIOR, J. P.; LIMA, E. C. Violência doméstica e sexual no âmbito da Estratégia de Saúde da Família: atuação profissional e barreiras para o enfrentamento. Physis Revista de Saúde Coletiva, Rio de Janeiro, v. 24, n. 3, p. 787-807, jul./set. 2014.

ROLIM, A. C. A. et al. Fatores associados à notificação de maus-tratos em crianças e adolescentes realizada por enfermeiros na Atenção Primária à Saúde. Rev. Latino-Am. Enfermagem, São Paulo, v. 22, n. 6, p. 10481055, nov./dez. 2014.

SONBOL, H. N. et al. Knowledge, educational experiences and attitudes towards child abuse amongst Jordanian dentists. Eur J Dent Educ, Oxford, v.16, n. 1, p. el58-e165, feb./may 2012.

ULDUM, B. et al. Danish dentists' and dental hygienists' knowledge of and experience with suspicion of child abuse or neglect. International Journal of Paediatric Dentistry, Oxford, v. 20, n. 5, p. 361-365, jul. 2010.

Recebido para publicação em abril de 2015

Versão final em setembro de 2015

Conflito de interesses: inexistente

Suporte financeiro: Fundação Cearense de Apoio ao

Desenvolvimento Científico e Tecnológico (Funcap), Edital de

Segurança Pública no 05/2008 